\title{
WHAT COMES AFTER THE LETTER
}

W hen I encounter Sophie Calle's work, what strikes me is the tension between its emotional vulnerability — such as the pain of a lover's abandonment in 'Take Care of Yourself' (2007)—and the 'objective' documentary evidence she employs through her use of photographs, interviews, and descriptive texts. The process of generating, utilising, and managing documents as art practice gained traction with the rise of conceptualism in the 1960s. According to Sol Lewitt, who helped define the term, 'It is the objective of the artist who is concerned with conceptual art to make his work mentally interesting to the spectator, and therefore usually he would want it to become emotionally dry' (Lewitt 1967: 79). However, conceptualism itself helped push against the idea of documentation as a 'transparent' medium, entering into a more complicated conversation about representation across multiple viewpoints, with artists such as Calle using it to explore the intersections between their own lived, personal experience, and that of others (Berger and Santone 2016).

It is with this shared interest in examining how lived experience is recorded and remembered that my collaborations with anthropologist Alyssa Grossman have taken shape. Our work together-which ranges from films to installations to experimental workshops-is a kind of conversation. We shuttle back and forth between the contexts of anthropology and art in an ongoing exchange, which often involves critically re-examining the assumptions inherent in our individual fields. Our work hinges on the long history of our personal friendship. It is the context of this friendship-inseparable from who we are as artist and anthropologist- that provides a catalyst to experiment within and between objective distance (to document, to re-contextualise, to analyse) and our subjective longings, dumb jokes, and personal affinities.

As a visual artist asked to respond to Alyssa's essay, I wondered what format or medium would be most appropriate. Taking Alyssa's own set of questions, and her essay title, as a jumping-off point, I became curious what might be revealed by 'stealing' a method from Sophie Calle, that is, by applying a set of rules to the archive of email correspondence that Alyssa and I have generated during our collaborative work and friendship over the years. I set a filter on this 'dossier' of evidence from our conversations, searching for sentences where the word 'document' appeared and another list generated by the terms 'feel/feeling.' The resulting text-my response to Alyssa's essay 'Stealing Sophie Calle'-is reprinted below.

\section{REFERENCES}

Berger, Christian and Jessica Santone 2016. Documentation as Art Practice in the 1960s. Visual Resources 32 (3-4): 201-209. https://doi.org/10.1080/01973762.2016.1241030.

LeWitt, Sol 1967. Paragraphs on Conceptual Art. Artforum 5 (10): 79-83.

SELENA KIMBALL

ASSISTANT PROFESSOR

CONTEMPORARY ART PRACTICE

PARSONS, THE NEW SCHOOL

selenakimball@gmail.com 


\section{AG 3.3.18 subject: index!}

I also thought that it could be interesting to include in our catalogue

other documents related to this PROCESS of indexing.

\section{SK 2.06.18 subject: re: calle article}

Dealing more directly with the framing, lighting, and isolation of the document of the artifact, maybe?

\section{AG 5.29.17 subject: workshop follow up}

4.) How did you document your observation during the workshop? Please upload these records as a JPG, PDF, or .MOV, or word document.

\section{SK 3.01.17 subject: Re: final draft?}

One note we don't have to figure out yet: I think we should professionally document the workshop, if possible, since this is as much about process/ collaboration/ encounter as result.

\section{AG 2.22.17 subject: abstract}

You sent me your first document by accident... Hope it wasn't THAT much in need of revision!

AG 2.28.16 subject: Professional History Section You can just send those to me in an email, and I'll add them to last year's document.

AG 9.11.15 subject: RE: thoughts while sanding By the way, I was perusing a copy of Documents that I found online a few weeks ago, and found this image on one of its pages. Weird coincidence, there is really something with these connections.

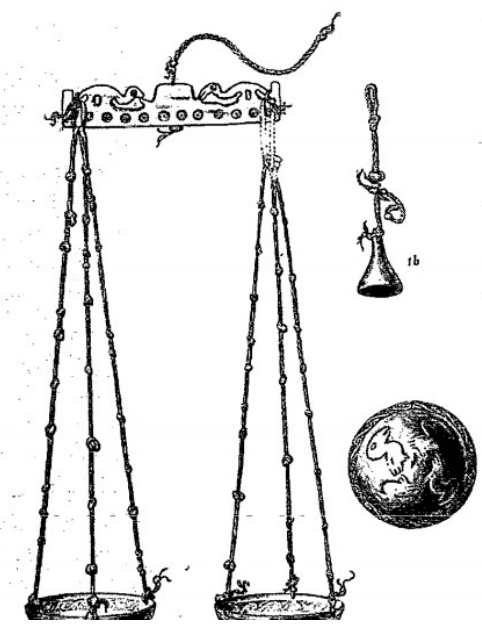

AG 5.09.18 subject: $h i$

I don't know if it is the heat or sunlight or what but I am feeling really odd.

SK 5.09.18 subject: Re: hi

(Spring weather always makes me feel terrible at first with weird body memories of Megan's death still so I can kind of relate.)

AG 5.02.18 subject: plans

I just feel a bit self-conscious going into this with only the vague idea of looking at Nordenskiöld's rock collection...(which by the numbers in the catalogue seems to be really vast, actually).

\section{AG 3.22.18 subject: slow time}

I get the feeling everyone is rooting for Larry, and wanting him to keep eating, keep doing exercises, moving around, but for what? Just so he can last another few days? I wish he could just let go.

\section{AG 3.06.18 subject: Re: stuff}

But it all just brings up that feeling of having to get back before it's too late, which was so difficult with my dad.

\section{SK 2.23.18 subject: Re: Friday talking}

I feel like l'm skimming some kind of fatty oilslicked surface-it stinks of rotting chicken. And the trains are all fucked up.

\section{AG 2.23.18 subject: Re: Friday talking}

Every time I hear you talk about your job I get the feeling that it is encroaching more, little by little, centimeter by centimeter...

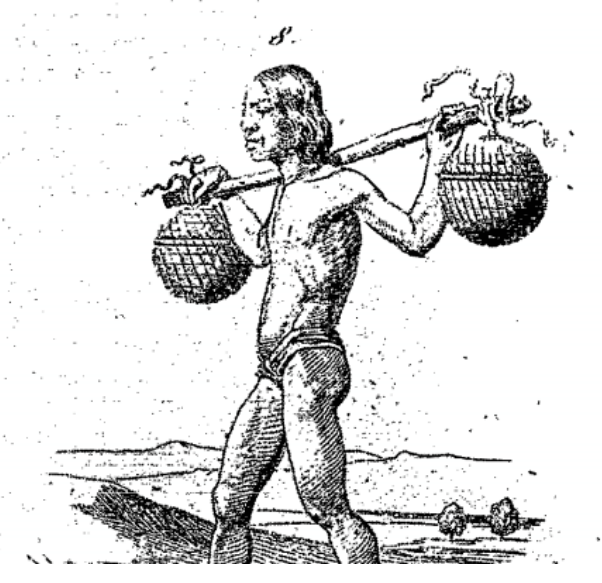


AG 5.12.15 subject: archives

First of all just this universe of objects and documents is something that we are no longer creating as a culture because email leaves no tangible traces. And then seeing the boxes of documents-- original tags the objects had, original cards with sketches of the objects. And then Nordenskiöld, the director between 1921 and 1935 or something like that, the one who contributed to the surrealist

journal Documents, Adriana knows a lot about him, and his approach and ideas and way of working.

|SK 4.27.15 subject: Re: question Hi A, "Undercover Surrealism: George Bataille and Documents"-Thanks for the discussion yesterday-

SK 3.05.15 subject: Re: Project Question!? But somehow I was seeing your document as something I could borrow from. (Steal from!)

AG 10.31.14 subject: day 1 of year 41

"Through these techniques of visual and textual collage, we are creating a new sort of document, turning the Museum's publication into a series of fictional objects and ethnopoetic commentaries."

AG 8.16.14 subject: saturday And now I recently found out that I have to give the Swedish Migration Board evidence of their UK nationality, so I've been working on it-figuring out which documents to get, what paperwork to send in.

AG 12.19.13 subject: romaniaaaa I guess the 'archival' footage from the 1990s is the most fascinating. And then the whole movement to professionalize and make it popular and cool, kind of a document of what has been going on in Romania as a whole.

SK 2.08.13 subject: What comes after the letter Dear A, I was searching for some tax documents this morning in a desk pile and came upon one of your letters.
AG 1.09.18 subject: Re: hi

I stayed home with Milo on Tuesday because he was feeling sick. Last week I stayed home with Theo for a day, because he had a fever. Today I had to pick up the kids early from school because Theo got an eye injury in the morning and he was feeling bad.

SK 10.08.16 subject: 10:30 pm

At first, from the sudden proximity of his body and the creepy stealth, I thought he was going to assault me. Then, I could feel he was going to overpower me and simultaneously realized he wanted my wallet.

AG 1.22.1 $\underline{5}$ subject: Re: Light

After you left, Milo kept saying to Maisie, 'Don't worry, Maisie, Selena will come again soon. Maisie is feeling a bit left out after Selena left. But it's okay, Maisie. You will be alright.'

SK 4.24.14 subject Re: info In the MRI I could feel some very physical "sounds". It was unlike anything l'd experienced before in terms of having two senses (touch and sound) collide.

AG 1.25.14 subject: Re: Foggy hellos

I just got home this evening from the hospital. My eyelids feel like cardboard. I am hobbling around and feeling like there's pillow stuffing coming out of my butt.

AG 8.26.13 subject: Re: money article revised Got my second ultrasound on wednesday. I've been feeling the baby move a lot recently. It's like little coughs in my stomach, the kicking.

SK 8.13.13 subject: Re: rainy manchester I often have the experience of feeling overwhelmed by all the lives lived by people all around me, each going in all their different directions...

AG 2.09.13 subject: Re: What comes after the letter Milo is shrieking right now about the car he sees outside. It's these simple things that can be so incredible. I wish I could feel that kind of excitement about seeing a car. 